\title{
COVID-19 Disease Complicated with Severe Pneumonia in a Patient with End Stage Renal Disease (ESRD): A Case Report from Bangladesh
}

\author{
Md. Reaz Uddin Chowdhury ${ }^{1 *}$ (D), Kazi Shanzida Akter², Muhammad Zahangir Alam¹, \\ Muhammad Anwarul Kabir'1, Sahedul Islam Bhuiyan³, Arifa Akram4, Sohel Rahman' \\ ${ }^{1}$ Abdul Malek Ukil Medical College, Noakhali, Bangladesh \\ ${ }^{2}$ Dedicated COVID-19 Hospital-Trauma Center, Feni, Bangladesh \\ ${ }^{3}$ Brahmanbaria Medical College, Brahmanbaria, Bangladesh \\ ${ }^{4}$ National Institute of Laboratory Medicine and Refferal Center, Dhaka, Bangladesh \\ ${ }^{5}$ Institute of Epidemiology Disease Control and Research, Dhaka, Bangladesh \\ Email: *mail2drreaz@gmail.com
}

How to cite this paper: Chowdhury, Md.R.U., Akter, K.S., Alam, M.Z., Kabir, M.A., Bhuiyan, S.I., Akram, A. and Rahman, S. (2020) COVID-19 Disease Complicated with Severe Pneumonia in a $\mathrm{Pa}$ tient with End Stage Renal Disease (ESRD): A Case Report from Bangladesh. Advances in Infectious Diseases, 10, 101-109. https://doi.org/10.4236/aid.2020.103010

Received: June 25, 2020

Accepted: July 26, 2020

Published: July 29, 2020

Copyright $\odot 2020$ by author(s) and Scientific Research Publishing Inc. This work is licensed under the Creative Commons Attribution International License (CC BY 4.0).

http://creativecommons.org/licenses/by/4.0/ (c) (i) Open Access

\begin{abstract}
Background: Since 2019, the pandemic of Coronavirus disease 2019 (COVID19) has spread very rapidly in China and Worldwide. COVID-19 is a highly contagious, infectious and rapidly spreading viral disease with an alarming case fatality rate up to $5 \%$. Case Report: In this article, we report a case of 60 years old non diabetic, hypertensive woman infected with COVID-19 who has end stage renal disease (ESRD) on hemodialysis for last 18 months. COVID19 patients with ESRD need isolation dialysis but most of them cannot be handled properly due to limited hemodialysis machine. With these unavailability and risk, we continue the treatment along with hemodialysis for controlling uraemia and fluid balance. With all effort this patient ended with an uneventful course with clinical improvement, improvement of all laboratory parameters and resolution of radiological findings but follow up RT-PCR cannot done due to changing guideline of discharge criteria of COVID-19 patient in Bangladesh. He positively responded to meropenem, clarithromycin, favipiravir, thromboprophylaxis with enoxaparin along with supplemental oxygen therapy. After that she was discharged with an advice of 14 days home isolation with regular hemodialysis and a follow up visit after 14 days in the outpatient department. Conclusion: An ESRD patient on regular hemodialysis suffering from severe pneumonia has high risk of mortality. Combined effort from the health care workers are needed to decrease the mortality of COVID-19 infected ESRD patients.
\end{abstract}


Keywords

ESRD, Hemodialysis, COVID-19, Pneumonia, Corona Virus

\section{Introduction}

Since December 2019, the epidemic of corona virus disease 2019 (COVID-19) has spread very rapidly in China and worldwide [1]. The virus that causes COVID19 was named severe acute respiratory syndrome corona virus 2 (SARS-CoV-2) [1]. Up to June 23, 2020, total confirmed corona virus cases were 119,198 with total number of death were 1545 and which was 9 (nine) death per million of population of Bangladesh [2]. Clinical characteristics of patients of COVID-19 infection have been reported as mild (Influenza like illness), moderate (pneumonia), severe (severe pneumonia), critical (ARDS, Sepsis/Septic shock) [3]. Patients with pre existing conditions can be more susceptible to COVID-19 and are likely to experience more severe disease including patients with chronic kidney disease, patients in chronic hemodialysis and those living with a kidney transplant [4]. End stage renal disease (ESRD) is a severe medical condition with a high prevalence of co morbid conditions including diabetes, hypertension and cardiovascular disease [5]. For patients with end stage renal disease on dialysis, management of patients on dialysis should be carried by strict adherence protocol to minimize the spread of infection [6]. Even though ESRD patients are particularly susceptible to COVID-19 infection and develop severe to critical disease, there are limited studies and case reports about COVID-19 in ESRD patients. We report a case of ESRD patient on regular hemodialysis with severe COVID-19 pneumonia. This report describes the clinical presentation of COVID19 in ESRD patient, process of diagnosis, the laboratory and imaging investigations, as well as the course of treatment. Most ESRD patients present with pneumonia/severe pneumonia in COVID-19 which leads to a challenge of management and high risk of morbidity and mortality.

\section{Case Presentation}

A 60 years old woman with end stage renal disease(ESRD) living in Bangladesh presented with fever for 3 days, cough, increasing breathlessness for 2 days and severe fatigue, anorexia for same duration. She has no history of diarrhoea, rhinorrhea or anosmia. Due to her increasing symptoms she got admitted in a hospital on 13 June, 2020. She told that her husband died 3 days before due to COVID-19. After admission she was advised for Chest X-ray, other laboratory investigations and Oropharyngeal swab for RT-PCR on 14 June, 2020 and came positive on 17 June, 2020. A review of the patients history showed that she had hypertension, ischemic heart disease and end stage renal disease (ESRD) was on regular three (3) times weekly hemodialysis through a radial-cephalic arteriovenous fistula for last 18 month. Her regular medication include amlodipine 5 
mg daily, bisoprolol $5 \mathrm{mg}$ daily, clopidogrel $75 \mathrm{mg}$ daily, prazosine $2 \mathrm{mg}$ twice daily, rosuvastatin $10 \mathrm{mg}$, nitroglycerine $2.6 \mathrm{mg}$ twice daily, calcitriol $0.25 \mathrm{mcg}$ once daily and losartan potassium $50 \mathrm{mg}$ once daily, frusemide $120 \mathrm{mg}$ daily and calcium acetate $667 \mathrm{mg}$ once daily, erythropoietin (mRNA) $5000 \mathrm{IU}$ weekly. On admission she was agitated, her temperature was $103^{\circledR}$ f, Respiratory rate was 33 breath/min, Heart rate was $106 / \mathrm{min}$, regular with normal volume, Blood pressure was $160 / 90 \mathrm{~mm}$ of $\mathrm{Hg}$, the patient was dyspnoeic with Saturation of oxygen $\left(\mathrm{SpO}_{2}\right)$ was $88 \%$ on room air, given supplemental oxygen $5 \mathrm{~L}-8 \mathrm{~L} / \mathrm{min}$ by simple face mask. After that her saturation became $96 \%$ on supplemental oxygen therapy. Following 2 days after admission she showed fluctuating oxygen saturation from $86 \%$ to $96 \%$, required continuous supplemental oxygen through simple face mask. Her physical examination revealed mild anaemia otherwise un-remarkable. On chest examination, she had symmetrical breath sounds bilaterally, with coarse inspiratory crackles bilaterally in the lower part of both lungs. Her cardiovascular examinations showed normal heart sounds with no added sounds and her jugular venous pressure was not raised. She did not have pitting leg oedema. Her abdominal and neurological examinations were unremarkable. The haemodialysis facility where the patient was receiving her scheduled dialysis took specific precautions to reduce transmission and protect the patients. The facility was disinfected properly.

On Chest X-ray posterior-anterior view of the patient showed (see Figure 1) non-homogenous and scattered ground glass opacities mainly distributed in the middle and outer zone of both lungs. Laboratory tests on admission showed (see Table 1) a white blood cell count (WBC) of $11,200 / \mathrm{cmm}$ with $70 \%$ neutrophils, $18 \%$ lymphocytes and 3\% eosinophils. Her hemoglobin (HB\%) was $9.5 \mathrm{gm} / \mathrm{dl}$, Erythrocyte sedimentation rate (ESR) was $65 \mathrm{~mm}$ in $1^{\text {st }}$ hour and her platelet count was $160,000 / \mathrm{cmm}$. Her urea was $120 \mathrm{mg} / \mathrm{dl}$, blood urea nitrogen (BUN) was 39.31 $\mathrm{mg} / \mathrm{dl}$, serum Lactate dehydrogenase (LDH) was $580 \mathrm{U} / \mathrm{L}$ and her serum creatinine was $5.9 \mathrm{mg} / \mathrm{dl}$. Her sodium was $131 \mathrm{mmol} / \mathrm{l}$, potassium was $5.2 \mathrm{mmol} / \mathrm{l}$, chloride was $106 \mathrm{mmol} / \mathrm{l}$, serum uric acid was $4.36 \mathrm{mg} / \mathrm{dl}$. Serum calcium was $7.99 \mathrm{mg} / \mathrm{dl}$ and Alanine Aminotransferase (ALT) was $40 \mathrm{U} / \mathrm{L}$. Her C reactive protein (CRP) was $72 \mathrm{mg} / \mathrm{L}$, serum ferritin was more than $1000 \mathrm{ng} / \mathrm{ml}$ and D-dimer was 0.24 $\mathrm{mg} / \mathrm{l}$, cardiac enzymes within normal limit. The patient was diagnosed with severe COVID-19 disease.

Initially her condition was stable with 6 - $8 \mathrm{~L} / \mathrm{min}$ supplemental oxygen therapy. Approximately 72 hours after admission she was needed additional monitoring after desaturation despite oxygen supplementation. She was started on an antibiotic regimen for COVID-19 as well as empiric antibiotic for possible co-infection. She received an initial course of azithromycin and doxycycline for 7 days. Then she received a 10 days course of antiviral Favipiravir along with 14 days course of meropenem and 5 days course of intravenous methylprednisolone $250 \mathrm{mg}$. The antibiotic doses have been adjusted for ESRD and haemodialysis. An ECG was done every alternate day to monitor the QT interval on antibiotic therapy. She was continuously needed high flow oxygen in a range of $12-15$ 


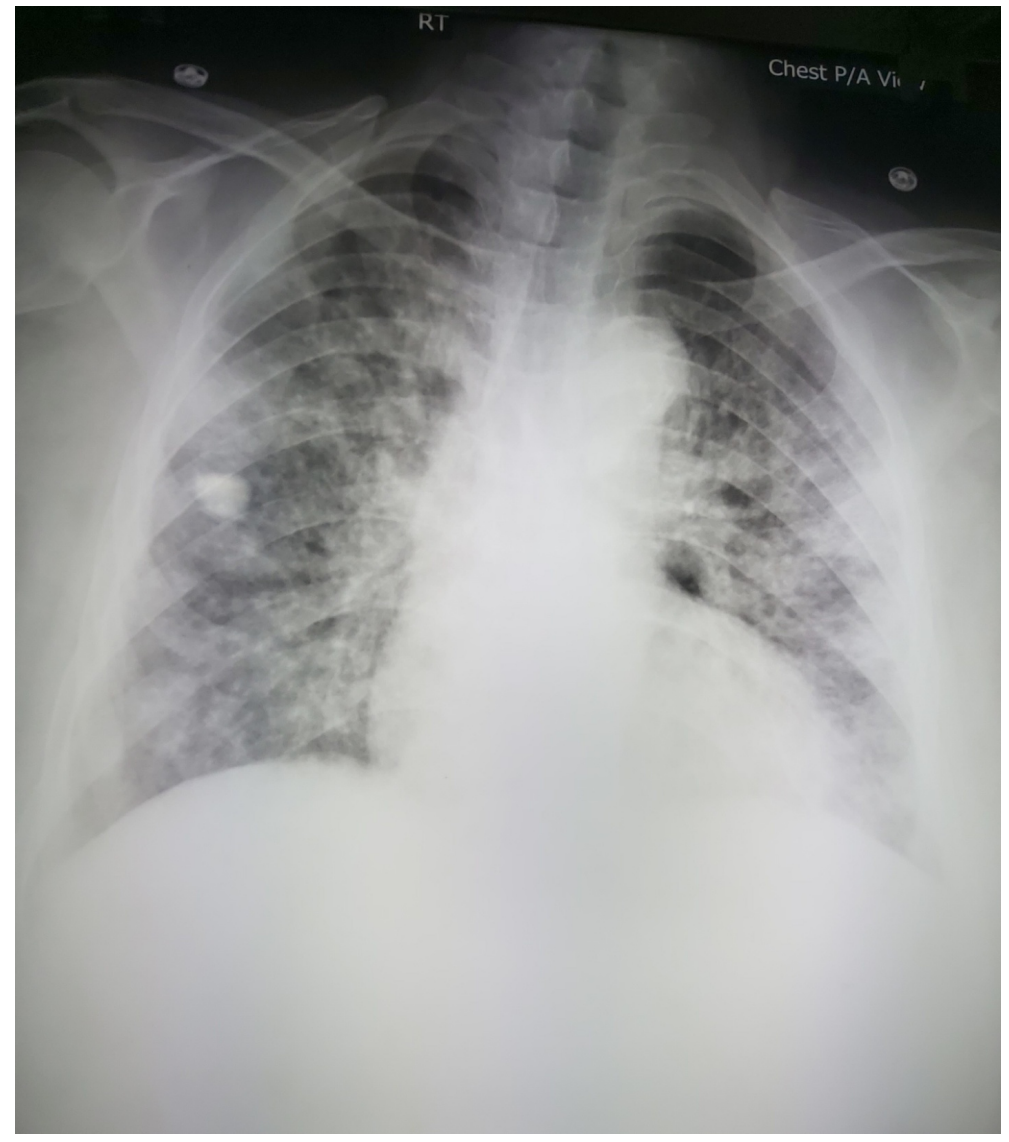

Figure 1. Chest X-ray posterior-anterior view taken on 13 June, 2020 showing non-homogenous and scattered ground glass opacities mainly distributed in the middle and outer zones of both lungs.

Table 1. Laboratory findings on admission.

\begin{tabular}{cc}
\hline Investigations: Jun 13, 2020 & Findings With Reference Range \\
\hline Hemoglobin (Hb) & $9.5 \mathrm{gm} / \mathrm{dl}(11.0-16.0 \mathrm{gm} / \mathrm{dl})$ \\
Erythrocyte Sedimentation Rate (ESR) & $65 \mathrm{~mm} \mathrm{in} 1^{\text {st }}$ hour $\left(0-10 \mathrm{~mm} \mathrm{in} 1^{\text {st }}\right.$ hour $)$ \\
Total White Blood Cell (WBC) count & $11,200 / \mathrm{cmm}(4000-11,000 / \mathrm{cmm})$ \\
Neutrophils (Differentials) & $70 \%(40 \%-75 \%)$ \\
Lymphocytes (Differentials) & $18 \%(20 \%-50 \%)$ \\
Eosinophils (Differentials) & $03 \%(02 \%-09 \%)$ \\
Platelet Count & $160,000 / \mathrm{cmm}$ \\
Serum Creatinine & $5.9 \mathrm{mg} / \mathrm{dl}(0.5-1.2 \mathrm{mg} / \mathrm{dl})$ \\
Alanine Aminotransferase (ALT) & $40 \mathrm{U} / \mathrm{L}(\mathrm{Up} \mathrm{to} 32 \mathrm{U} / \mathrm{L})$ \\
C reactive protein(CRP) & $72 \mathrm{mg} / \mathrm{dl}(<8 \mathrm{mg} / \mathrm{L})$ \\
Sodium & $131 \mathrm{mmol} / \mathrm{l}(135-145 \mathrm{mmol} / \mathrm{l})$ \\
Potassium & $5.2 \mathrm{mmol} / \mathrm{l}(3.5-5.3 \mathrm{mmol} / \mathrm{l})$ \\
Chloride & $106 \mathrm{mmol} / \mathrm{l}(98-107 \mathrm{mmol} / \mathrm{l})$ \\
D-dimer & $0.24 \mathrm{mg} / \mathrm{l}(<0.5 \mathrm{mg} / \mathrm{l})$ \\
\hline
\end{tabular}




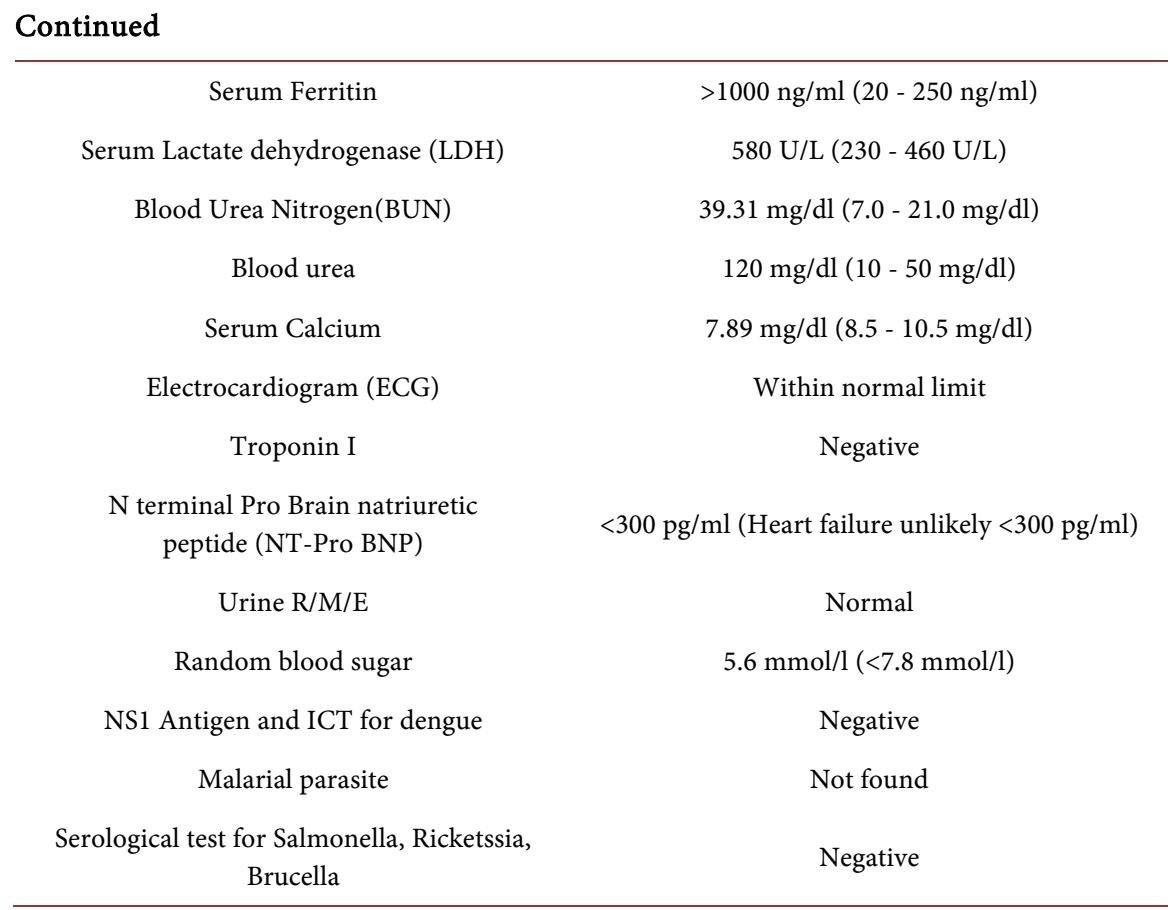

L/min through a non-rebreather mask. She was responded gradually to medical therapy. She continued to receive her scheduled hemodialysis from the nearby hemodialysis unit with supplemental oxygen with all aseptic precaution. After 21 days in the hospital her condition improved clinically. She was again shifted to simple face mask $(5-8 \mathrm{~L} / \mathrm{min}$ ) for giving oxygen and she gradually not needed supplemental oxygen. The radiological improvement lagged behind the improvement of clinical condition, her repeat chest X-ray showed bilateral resolution of the opacities though non homogenous opacity still evident in the right lung (see Figure 2) and improvement of all laboratory parameters (see Table 2). A repeat RT-PCR cannot done for changing discharge criteria of COVID-19 patients in the guideline of Bangladesh. After that she was discharged with proper medication, also advised for home isolation for another 14 days with regular hemodialysis and a follow up visit in the outpatient department after 14 days.

\section{Discussions}

COVID-19 infection is a rapidly developing field and we should expect more infected ESRD patients' case report and analysis. COVID-19 pneumonia appears to be the most common serious manifestations of the disease. It is predominantly characterized by fever, cough, dyspnoea and bilateral infiltrates on chest imaging [7]. The patient was diagnosed based on the ministry of health in Bangladesh national guidelines on Clinical Management of Coronavirus disease 2019 (COVID-19) version 7. She was levelled as suspected based on close contact with her husband died of COVID-19 and presenting with respiratory symptoms, fever, imaging features suggestive of COVID-19 pneumonia as well as presence of very high acute phase reactant protein after admission [8]. Our patients exhibited 


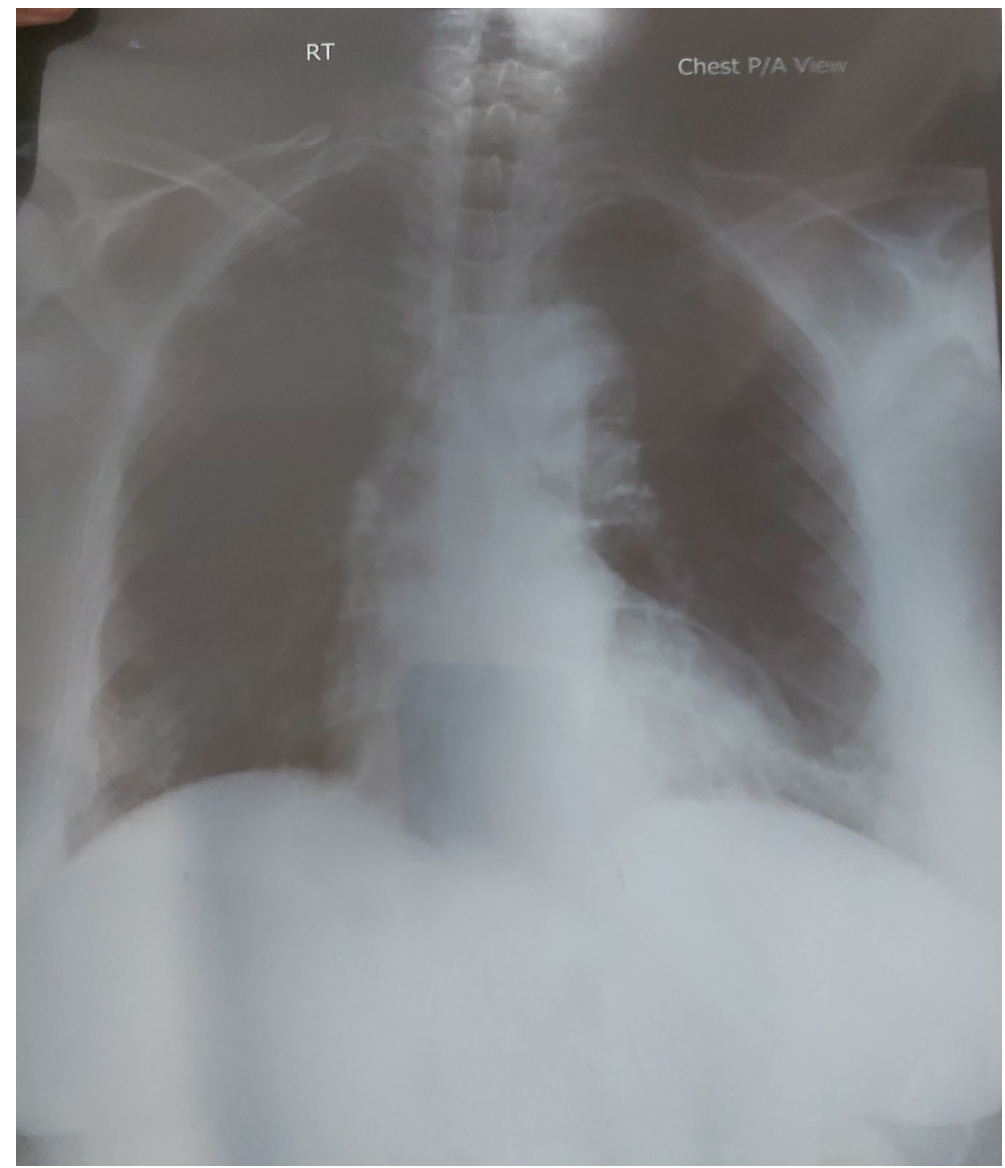

Figure 2. X-Ray Chest posterior-anterior view taken before discharge (Follow up on 30 June, 2020) showing absorption of bilateral opacity though mild non homogenous opacity seen in the lower part of both lungs mostly in the right lung.

Table 2. Laboratory findings before discharge from hospital.

\begin{tabular}{cc}
\hline Investigations: July 5, 2020 & Findings With Reference Range \\
\hline Hemoglobin (Hb) & $9.8 \mathrm{gm} / \mathrm{dl}(11.0-16.0 \mathrm{gm} / \mathrm{dl})$ \\
Erythrocyte Sedimentation rate (ESR) & $50 \mathrm{~mm} \mathrm{in} 1^{\text {st }}$ hour \\
Total White blood cell (WBC) count & $9800 / \mathrm{cmm}(4000-11,000 / \mathrm{cmm})$ \\
Neutrophils (Differentials) & $74 \%(40 \%-75 \%)$ \\
Lymphocytes (Differnetials) & $21 \%(20 \%-50 \%)$ \\
Eosinophils (Differentials) & $03 \%(02 \%-09 \%)$ \\
Serum Creatinine & $6.1 \mathrm{mg} / \mathrm{dl}(0.5-1.2 \mathrm{mg} / \mathrm{dl})$ \\
Alanine Aminotransferse (ALT) & $24 \mathrm{U} / \mathrm{L}(\mathrm{Up}$ to $32 \mathrm{U} / \mathrm{L})$ \\
Sodium & $139 \mathrm{mmol} / \mathrm{l}(135-145 \mathrm{mmol} / \mathrm{l})$ \\
Potassium & $5.5 \mathrm{mmol} / \mathrm{l}(3.5-5.3 \mathrm{mmol} / \mathrm{l})$ \\
Chloride & $106 \mathrm{mmol} / \mathrm{l}(98-107 \mathrm{mmol} / \mathrm{l})$ \\
C reactive Protein (CRP) & $10.4 \mathrm{mg} / \mathrm{l}(<8 \mathrm{mg} / \mathrm{l})$ \\
Serum Ferritin & $631 \mathrm{ng} / \mathrm{ml}(20-250 \mathrm{ng} / \mathrm{ml})$ \\
Blood urea & $61 \mathrm{mg} / \mathrm{dl}(10-50 \mathrm{mg} / \mathrm{dl})$
\end{tabular}


laboratory findings common among the COVID -19 patients [9]. She had lymphopenia as well as raised inflammatory markers (ESR, CRP, Ferritin).

Typical radiographic findings in the chest X-rays of COVID-19 pneumonia were consolidation and ground glass opacity, with bilateral, peripheral and lower lung zone distributions. Our patient had typical chest X-ray findings (Figure 1) thus CT scan of chest not needed for diagnosis. Previous studies suggest that COVID-19 in people with chronic co-morbidities can more easily become a critical illness or cause death [10]. This patient developed severe pneumonia within 4 days of onset of symptoms due to immunocompromised status. It has been confirmed that T-cell immunity is a key factor in recovery from SARS-CoV-2 infection [11]. Because uraemia status is associated with extensive impairment of lymphocyte and granulocyte function, an abnormal immune system may alter the response of SARS-CoV-2 infection [12].

The COVID-19 treatment approach remains uncertain with no therapies clearly proven benefit. In addition to supportive care, the patient was started on a COVID-19 regimen composed of azithromycin, favipiravir, meropenem and methylprednisolone [3]. Maintaining hemodialysis is most important factor for a ESRD patient with severe pneumonia because of limited resource of isolation dialysis and limited dialysis in every hospital.

This is particular concern given the density of dialysis facility in our country, creating a high risk for exposure. So we take all aseptic measure to prevent spread. In our case, the patient has to go into another hospital for taking hemodialysis. This scenario presents various epidemiological challenges as far as containing infectious spread in the dialysis unit. This scenario also suggests that home dialysis may be a protective intervention in the context of such a rapidly infectious disease but still not feasible in a lower middle class economic country like Bangladesh. So more dialysis facility, protection suits and protective quality mask for the health care workers are needed to combat the COVID-19 crisis, and more intensive care unit should build up urgently to decrease the mortality of COVID19 infected patients with severe presentation with co morbidities like end stage renal disease(ESRD).

\section{Conclusion}

ESRD patients with COVID-19 can present with severe/critical disease within early onset of the disease. So multi dimensional treatment approach should applied promptly to reduce mortality and to avoid exposure to heath care stuffs and other hemodialysis patients. COVID-19 therapy in ESRD is very challenging due to the adjustment of renal dose of various medications. So it is essential to make a simple and easier recommendation for the physicians. Further observational studies will be needed to more fully understand the full spectrum of clinical features and optimal diagnostic tools and treatment protocol for a COVID-19 disease in end stage renal disease (ESRD). 


\section{Statement of Ethics}

Informed consent was obtained from the patient for publication of this case report.

\section{Acknowledgements}

To all the stuffs of Medinova Specialized Hospital for their tremendous support and Dr Haider Clinic Hemodialysis unit for maintain strict isolation dialysis of the patient.

\section{Conflicts of Interest}

The authors declare no conflicts of interest regarding the publication of this paper.

\section{References}

[1] World Health Organization Official Website. https://www.who.int

[2] Novel Corona Virus (COVID19) Situation Reports. World Health Organisation.

[3] National Guideline on Clinical Management of Coronavirus Disease 2019 (COVID19). https://www.dghs.gov.bd

[4] Naicker, S., Yang, C.-W., Hwang, S.-J., et al. (2020) The Novel Coronavirus 2019 Epidemic and Kidneys. Kidney International, 97, 824-828. https://doi.org/10.1016/j.kint.2020.03.001

[5] System USRD. National Institute Heal National Inst Diabetes Dig Kidney Dis. 2018. 2018 USRDS annual Report: Epidemiology of Kidney Disease in the United States; $1-78$.

[6] CDC Mar 2020, International Society of Nephrology Mar 2020, European Renal Association-European Dialysis and Transplant Association.

[7] Wang, D., Hu, B., Hu, C., et al. (2020) Clinical Characteristics of 138 Hospitalized Patients with 2019 Novel Coronavirus-Infected Pneumonia in Wuhan, China. JAMA, 323, 1061-1069. https://doi.org/10.1001/jama.2020.1585

[8] Gao, Y., Li, T.T., Han, M.F., et al. (2020) Diagnostic Utility of Clinical Laboratory Data Determinations for Patients with the Severe COVID-19. Journal of Medical Virology, 1-6. https://doi.org/10.1002/jmv.25770

[9] Diagnosis and Treatment Protocol for Novel Corona Virus Pneumonia (Trial Version 7).

http://www.kankyokansen.org/uploads/uploads/files/jsipc/protocol v7.pdf2020

[10] Huang, C., Wang, Y., Li, X., et al. (2020) Clinical Features of Patients Infected with 2019 Novel Coronavirus in Wuhan, China. Lancet, 395, 497-506. https://doi.org/10.1016/S0140-6736(20)30183-5

[11] Liu, W.J., Zhao, M., Liu, K., et al. (2017) T-Cell Immunity of SARS-CoV: Implications for Vaccine Development against MERS-CoV. Antiviral Research, 137, 82-93. https://doi.org/10.1016/j.antiviral.2016.11.006

[12] Wong, P.N., Mak, S.K., Lo, K.Y., et al. (2003) Clinical Presentation and Outcome of Severe Acute Respiratory Syndrome in Dialysis Patients. American Journal of Kidney Diseases, 42, 1075-1081. https://doi.org/10.1016/j.ajkd.2003.08.005 


\section{Abbreviations}

COVID-19, Coronavirus disease 2019,

RT-PCR, Reverse transcriptase polymerase chain reaction,

ESRD, End stage renal disease,

ARDS, Acute respiratory distress syndrome. 